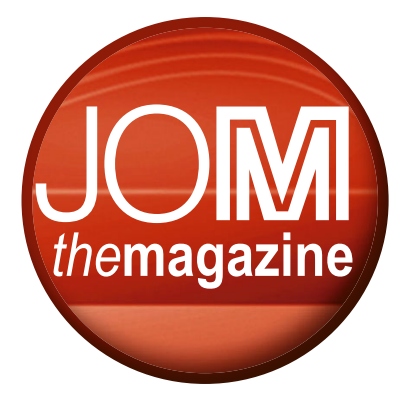

\title{
Congratulations to CAREER Grant Awardees; TMS Members Recognized for Professional Contributions
}

\section{member news}

Share the good news about your professional accomplishments in the pages of JOM. Contact Lynne Robinson, Magazine Editor, JOM, at Irobinson@ @tms.org with your information. Please note that only current TMS members can submit items for consideration to Member News.

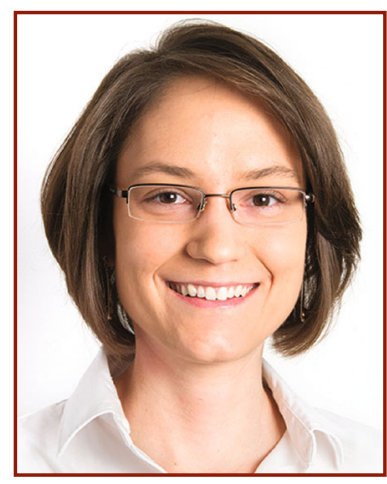

Allison Beese

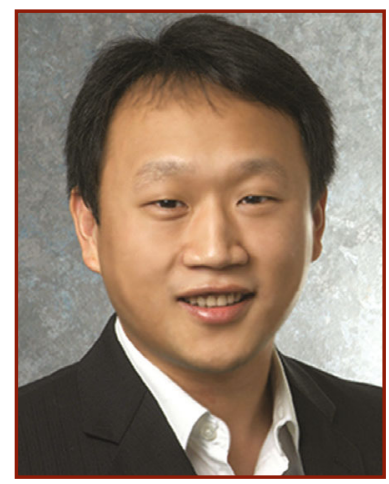

Bo Li

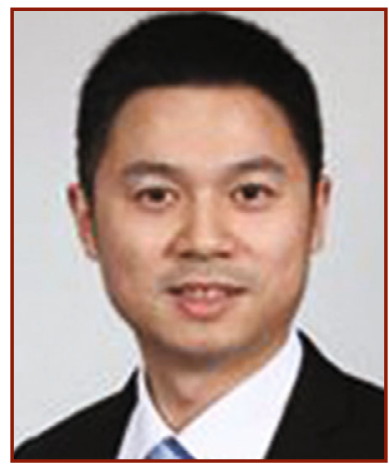

Caizhi Zhou

\section{TMS Members Honored with CAREER Grants}

TMS extends congratulations to six young professional members who have received grants from the National Science Foundation's (NSF) Engineering Directorate through the Faculty Early Career Development (CAREER) program. The CAREER program provides support to promising junior engineering faculty, allowing them to pursue impactful research while also serving as committed educators. The members being recognized with CAREER grants are:

Allison Beese, Pennsylvania State University.

Project: "Investigating the Micromechanics of Fracture in Additively Manufactured Metals."

Bo Li, Case Western Reserve University. Project: "A Predictive Modeling and Simulation-Based Certification Framework for Additive Manufacturing of Metals."

Caizhi Zhou, Missouri University of Science and Technology.

Project: "Understanding Interface-Mediated

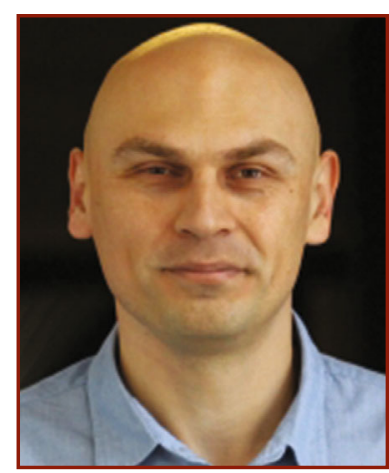

Marko Knezevic

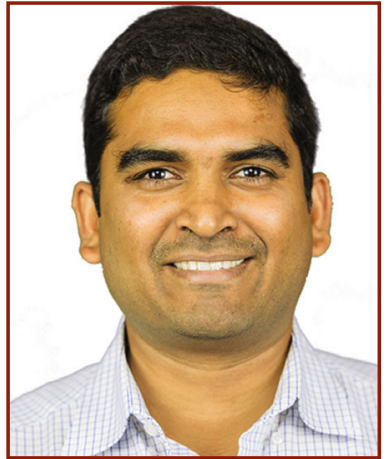

Siva Nadimpalli
Deformation in Layered Composites through Modeling and Experiment."

Marko Knezevic, University of New Hampshire.

Project: "An Experimentally-Informed Multi-Level Framework for Modeling Fracture of Hexagonal Metals."

Siva Nadimpalli, New Jersey Institute of Technology.

Project: "Electro-Chemo-Mechanics of Polymer/Active Material Interface Fracture."

Iryna Zenyuk, Tufts University. Project: "Mechanisms of Ion Transport in Ionomer-Free Electrodes."

For Early Career TMS Members TMS offers a number of resources specifically designed to meet the needs of young professional members. These include leadership development programs and opportunities to connect with mentors and gain professional exposure. Visit tms.org/YoungProfessionals to learn more. 


\section{David Bourell Named SME Award Recipient}

David L. Bourell, Temple Foundation Professor, The University of Texas at Austin, was honored with the 2017 Albert M. Sargent Progress Award by the Society of Manufacturing Engineers (SME) at the SME International Awards Gala on April 30. He was specifically cited for "his fundamental and applied research on additive manufacturing materials, their subsequent industrial use and the publications that share the associated knowledge." The Sargent Award is one of six International Honor Awards that SME confers annually to recognize significant contributions to manufacturing. A 2011 TMS Fellow, Bourell is also the inaugural chair of the TMS Additive Manufacturing Committee and received the 2009 TMS Materials Processing and Manufacturing Division Distinguished Scientist/ Engineer Award.

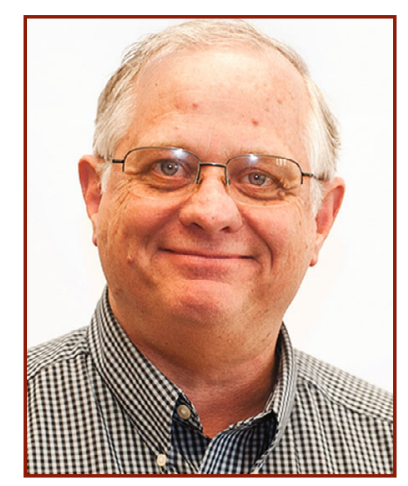

David L. Bourell

\section{MPIF Recognizes TMS Members}

The Metal Powder Industry Federation (MPIF) awarded its Distinguished Service to Powder Metallurgy Award to Iver E. Anderson and Diran Apelian on June 14.

Iver E. Anderson, senior metallurgist, Ames Laboratory, is a 2015 TMS Fellow. He counts the 2014 Application to Practice Award and the Alexander Scott Distinguished Service Award among his many other TMS recognitions. He was also inducted into the National Inventors Hall of Fame in 2017.

Diran Apelian is the Alcoa-Howmet Professor of Engineering and founding director of the Metal Processing Institute at Worcester Polytechnic Institute. A 2006 TMS Fellow, Apelian served as the 2008 TMS President. He has received numerous awards and honors, including the 1992 AIME Champion $\mathrm{H}$. Mathewson Award, the 2004 TMS/ASM Joint Distinguished Lectureship in Materials and Society Award,

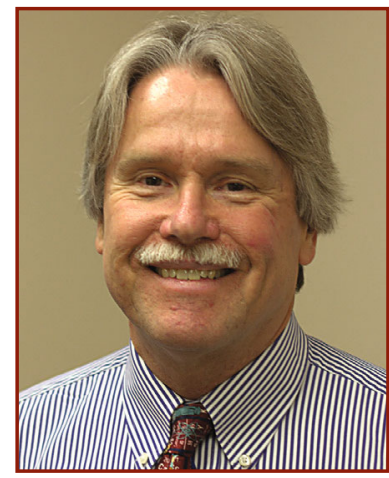

Iver E. Anderson

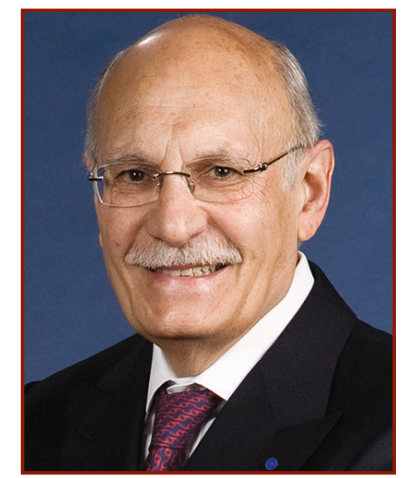

Diran Apelian the 2006 Bruce Chalmers Award.

The MPIF Distinguished Service Award recognizes individuals who have actively served the North American powder metallurgy industry with distinction for at least 25 years.

\section{Pradeep Rohatgi Honored by AFS}

Pradeep Rohatgi, Professor, University of Wisconsin-Milwaukee, received the Award of Scientific Merit from the American Foundry Society (AFS) in May. He was recognized for "significant contributions over 50 years to the metalcasting industry in research presentations at AFS events, and the education of casting engineers." A TMS member since 1963, Rohatgi is a 2012 TMS Fellow and recipient of the 2014 Bruce Chalmers Award.

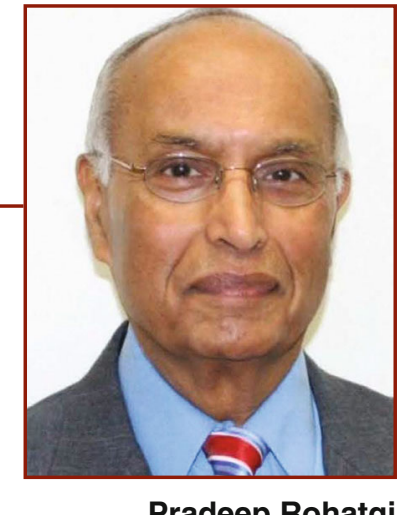

Pradeep Rohatgi

\section{Paul Ohodnicki Receives Carnegie Science Award}

Paul Ohodnicki, Federal Project Manager, National Energy Technology Laboratory (NETL), received the Advanced Manufacturing and Materials Award conferred by the Carnegie Science Center as part of its Carnegie Science Awards program to recognize and promote outstanding science and technology achievements in western Pennsylvania. He and NETL's Materials Science and Functional Materials Team were specifically recognized for demonstrating a cutting-edge sensor technology capable of measuring temperature and gas composition inside solid oxide fuel cell systems, holding promise for commercialization and job growth. Ohodnicki is a 2010 recipient TMS Functional Materials Division Young Leaders Professional Development Award.

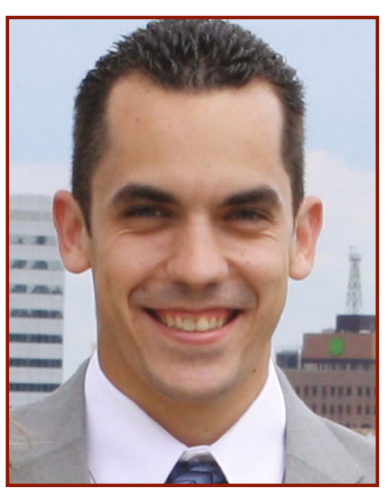

Paul Ohodnicki 